\title{
Opportunities and challenges for the building monitoring systems in the age-pandemic of COVID-19: Review and prospects
}

\author{
Safaa N. Saud Al-Humairi ${ }^{1}$. Ahmad Aiman A. Kamal ${ }^{1}$
}

Received: 30 November 2020 / Accepted: 27 December 2020 / Published online: 12 January 2021

(c) Springer Nature Switzerland AG 2021

\begin{abstract}
The latest COVID-19 pandemic outbreak posed a significant risk to millions of people worldwide who are safe and wellbeing. As the environment continues to be open from lockdowns and becomes unprecedentedly tenuous or what many called a "new norm," it makes sense to focus on what the society has experienced, re-examine our fundamental beliefs, and map the path of designing and creating a sustainable world. This article has summarized the latest technologies that have been recently implemented to control the spreading of COVID-19 through embedded smart monitoring systems and communicate effectively with the building management infrastructure. This article also discussed the statistical research analysis, which motivates the achievement of the targeted sustainable development goals (SDGs). Last but not least, the implemented technologies and their related variables to be controlled, challenges, and new perspectives were also addressed.
\end{abstract}

\section{Introduction}

At the end of 2019, a coronavirus was discovered in China, and it has been spread worldwide ever since until 2020. A lot of countries have faced economic crash since the existence of COVID-19. This virus has caused many companies to shut down, and it affects the country's financial side. Despite the virus that still exists, engineers and scientists try their very best to innovate and discover a new cure to fight against this virus [1,2].

COVID-19 is a virus that attacks the respiratory tract, causing trouble in breathing, fever, and cough. This virus spreads mainly through close contact and coughing and sneezing, which is not considered an airborne disease. The droplets from an infected person can spread to other individuals. More future technology developments are coming through in this era, and much equipment can detect certain diseases [3]. The most commonly used tool to detect diseases like fever is a thermometer gun used in every building, restaurants, and malls. To follow the SOP (standard operating procedure) implemented by the government $[4,5]$, they have to get records of body temperature from each person,

Safaa N. Saud Al-Humairi

safaa_najah@msu.edu.my

1 Faculty of Information Sciences and Engineering, Management and Science University, 40100 Shah Alam, Selangor, Malaysia phone number, time, and date. This system is to ensure to have forms of data if there are any future outbreaks. They must scan the visitor's temperature as a safety measure to ensure that none of them brings a disease through. Although it is not the primary diagnostic tool to identify a person's coronavirus symptom, it acts as a security measure [6].

The Internet of things (IoT) has, on the other hand, changed people's way of life, business, and interaction [7, 8]. As a result, the smart, more complex, more connected buildings and homes are becoming. This massive link leads to new efficiencies and capabilities and gives customers, companies, and cities tremendous value. However, these benefits pose significant challenges and cybersecurity risks because the COVID-19 pandemic crisis, protecting intelligent homes and intelligent buildings from cybersecurity hazards, is becoming more critical than ever. Smart cameras, wearables, and telecommunications are widely used to keep people in touch with their businesses, doctors, governments, schools, friends, and families. Using modern technology, people are productive for their work and home maintenance and more susceptible to threat attacks by actors who continue to exploit human nature to cash. Based on the Scopus data accessed on September 05, 2020, extensive researches were carried out on the topic of "Smart Building and Monitoring System" according to the statistical analysis provided in Fig. 1(a-c).

Monitoring systems are critical in helping the community store the data capable of supporting the police, medical, and 


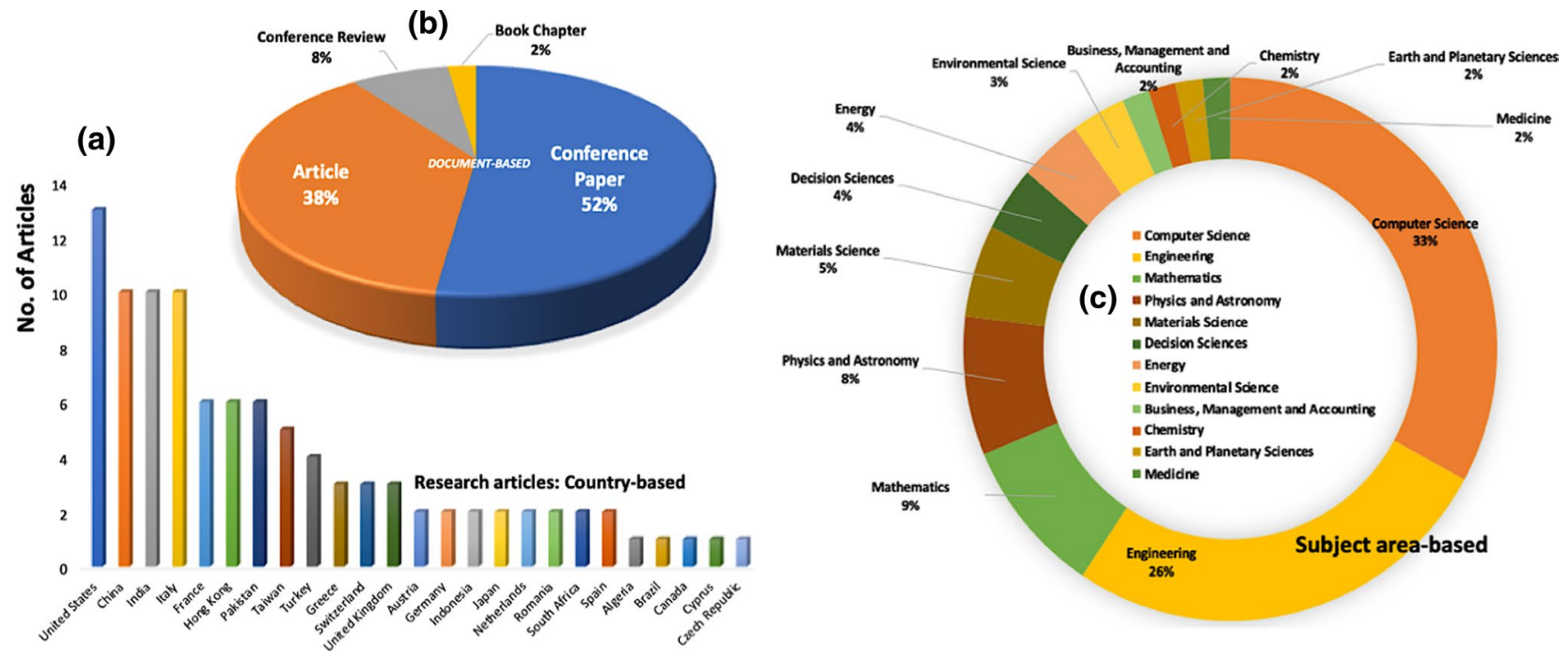

Fig. 1 Scopus data analysis with keywords of "Smart Building and Monitoring System" provides a statistical analysis on research article: a country based, b document based, and $\mathbf{c}$ subject area based

fire departments. These monitoring systems are considered to have closed-circuit cameras as it can record data of date, video or picture, and even time. This paper summarizes the recent technologies that have been implemented to tackle the spreading of COVID-19 and thus help society and communities to overcome this viral crisis.

\section{Types and implementations of smart infrastructure building}

The smart infrastructure building is mainly utilized to help society as one target of sustainable development goals (SDG) to provide a healthy and well-being life and help the medical authorities find infected individuals [9]. It can be used in buildings and even in many different applications. For instance, it can be used in apartments, hotels, malls, and many more. These technologies' advantages are to detect a specific body temperature by using infrared scanning and alert the management or the authorities $[10,11]$. Moreover, it could alert the management, but it also has face recognition to send details and information to the management via email or mobile application $[12,13]$.

Most companies would benefit a lot, which can help secure the building's safety and be cautious of future accidents or outbreaks. For instance, when people still have to go to work, this technology can be used as auto-surveillance inside the buildings to monitor their staff, residents, or pedestrians in monitoring their body temperatures as the first sign of safety. This monitoring system could help as well in easing the community and also a security measurement. Figure 2 shows the various monitoring technologies implemented to give a secure view against COVID-19 spreading.

\section{Swann thermal sensing PIR security camera}

This type of security camera feature called Swann's True Detect PIR Thermal Sensing technology [14] can reliably detect moving objects that generate heat, such as people or any related heat sources. It could also have more reliable notifications, record with more accurate motion detection, and eliminate false triggers such as dropping leaves, bugs, and rain. The camera's bullet shape makes it more visible for potential intruders to resolve 5MP, night vision distance of $30 \mathrm{~m}$, and PIR sensor within a distance of $10 \mathrm{~m}$. The camera's viewing angle is 70 degrees and can be used either indoors or outdoors with an IP66 rating. The security cameras are usually implemented in the house, outdoor, buildings, and also apartments.

\section{Swann 1080p alert indoor security camera}

This security camera [15] is not a better comparison to its thermal sensing PIR security camera because it does not have certain features. It is simple for house use and can be a baby monitor system as a budget option. The video quality is 1080 p full HD, but it has a much higher viewing angle within a $110^{\circ}$ range. It has a thermal and heat sensing PIR up to $10 \mathrm{~m}$ sensing distance, which is not as far from their thermal sensing PIR security camera as it has $30 \mathrm{~m}$ of range night vision distance which has the same distance limit of $10 \mathrm{~m}$. It also uses a secure cloud and internal offline backup for storing its recording data. 
Fig. 2 Different types of body temperature monitoring as portable and fixed devices

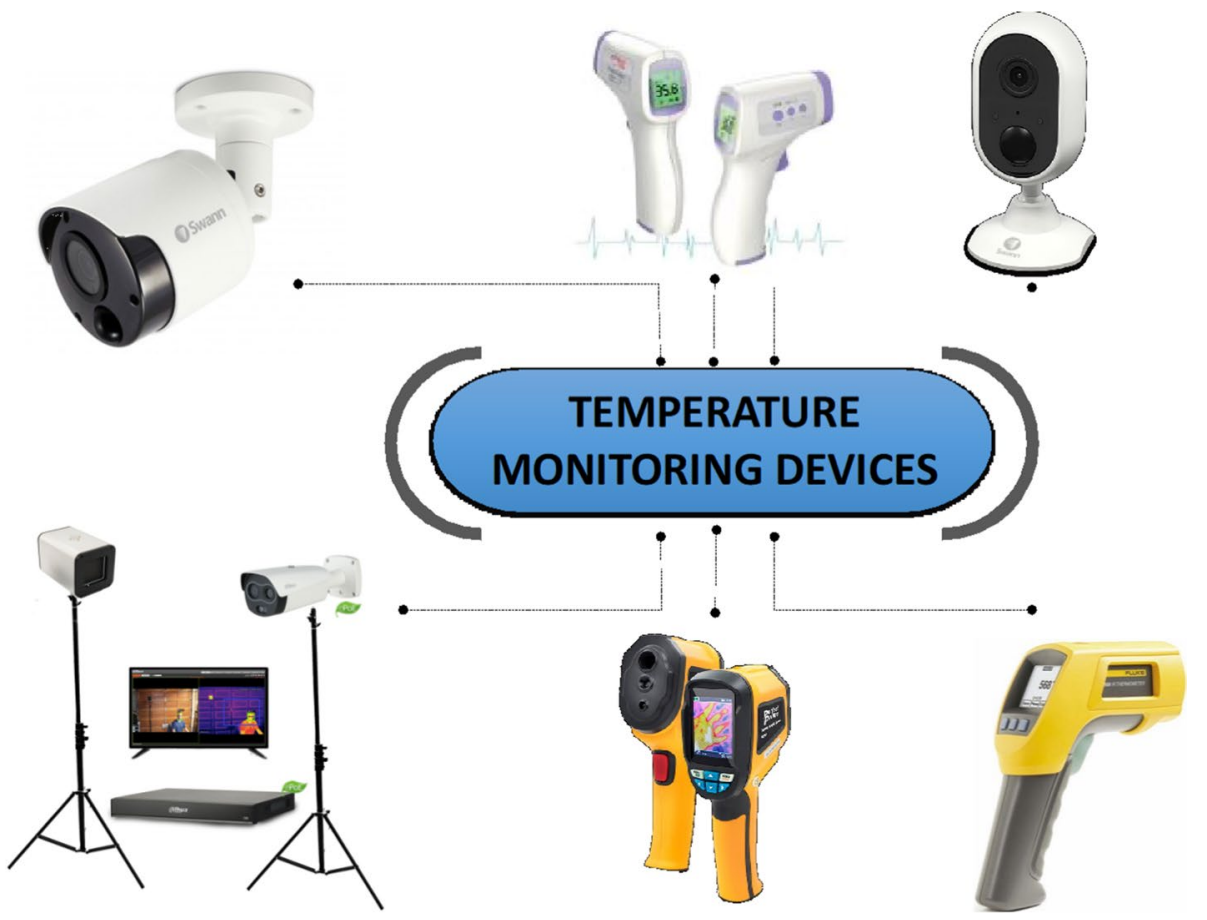

This camera also has two-way input and output audio as a microphone and speaker, respectively. The audio range from two cameras is $5 \mathrm{~m}$ and also equipped with a siren. The downside of this camera is that it can only be used indoors. Still, this camera's primary purpose is to have easy installation as it does not use any hubs or DVR, as it only connects through Wi-Fi and can be monitored online through their application software. The primary target is for such a lowcost use of home security systems, but maintaining thermal security cameras' outdoor use.

\section{Yobekan KV-11 non-contact infrared thermometer}

Yobekan has a contactless infrared thermometer gun that does not cost a lot to manufacture and produce. Since it is contactless to check a person's body temperature with a limited distance of 3 to $5 \mathrm{~cm}$ from the forehead, the accuracy of detecting a person's body temperature is $32{ }^{\circ} \mathrm{C}$ to $42.9^{\circ} \mathrm{C}$ and an object from $0{ }^{\circ} \mathrm{C}$ to $50{ }^{\circ} \mathrm{C}$. It also has an internal capacity memory of 30 assemblies of readings recall, and it recognizes all 30 scans with an auto-temperature converter from Celsius or Fahrenheit. It mainly uses this camera in front of restaurants, hospitals, or security doors.

\section{Fluke 568 contact and infrared temp gun}

Infrared thermometer Fluke 568 [16] is a combination of contact and contactless thermometer, and it offers a broader temperature range than most other infrared thermometers while providing more user-controlled features via an intuitive graphical display and thermal menu analysis. The simple on-screen three-button menu interface is programmed to be displayed in seven languages with a quick to use and employing user-friendly measurements. It only takes a few pushes of a button to change emissivity, record data, or switch on and off alarms. The distance-to-spot ratio of 50:1 allows you to assess smaller items from further afield, which gives easy access to advanced features with soft-key buttons and graphical display. The system can capture up to 99 data points for quick download via USB connection to a PC and includes FlukeView $®$ Forms software to analyze trends and data quickly. It can be switched on via USB from your laptop to extend battery life and quickly identify issues with the functions MIN, MAX, AVG, and DIF. It is also featured with a confident measurement of a wide range of surfaces with adjustable emissivity and a built-in table of materials. With a two-level backlight, it adapts easily to the lighting conditions and instantly alerts the audible and visual alarms to measure outside set limits and provide an accuracy of $1 \%$ per measurement.

\section{PerfectPrime IR0001 thermal camera}

The thermal imaging camera IR0001 [17] is the best cheap thermal camera used to detect leaks and identify problem areas within household insulation. It is assured to deliver reliable and accurate results with several different features to adjust depending on its application. It has $32 \times 32$, 1024 pixels and a temperature range of $-20{ }^{\circ} \mathrm{C}$ to $300{ }^{\circ} \mathrm{C}$. Its accuracy temperature is $\pm 2 \%$. This thermal camera is 
competitive in the market as its price is low, and it uses a cheaper component of the IR sensor as it is only a grid of $32 \times 32$. It causes the cost to lower down a little but still maintains an expensive thermal gun's function and features. The range of this exact model is from 0.5 to $4.5 \mathrm{~m}$ for accurate temperature scanning.

\section{Recent research on smart infrastructure buildings}

\section{WSN- and IOT-based smart homes and their extension to smart buildings}

SEAT, Massey University, Palmerston North 4442, New Zealand, conducts this research to explain the design and develop a reliable, efficient, flexible, economical, real-time, and realistic network of wellness sensors for smart home systems [18]. The heterogeneous sensor and actuator nodes are deployed into the home environment, based on wireless networking technologies. Such nodes produce real-time data about the use and movement of objects within the home to forecast an individual's wellness. Wellness here stands for how effectively someone stays fit in the home environment and performs their daily routine to lead a long and healthy life. They intend to initiate the research to implement the smart home approach and introduce it to track an inhabitant's behavior for wellness detection under different home conditions (other houses). Besides, their work extends the smart home concept to intelligent buildings and models the design issues pertaining to the smart building environment; these design issues are related to concept efficiency and reliability. This research paper also explores how the ISM band interference and attenuation losses can be mitigated without sacrificing optimum system efficiency.

Different types of devices are used to build a network using the smart and intelligent home monitoring system of a Zigbee-based Digi XBee Series 2 as an RF module. This system combines heterogeneous sensors that include PIR sensors, temperature, force, and electrical devices. The feature overview of smart home wellness monitoring is shown in Fig. 3. The intelligent home systems have been designed to independently control the well-being of elderly persons living in their own homes. The built-in smart home system can monitor an inhabitant's general physical and physiological activities and the environment at one time. It is a multi-model, non-invasive new sensor that is mounted on the central location of the house. The continuous internal control can be accomplished with a single local home gateway server computer. In a work environment for Windows appliances, the software modules are designed to evaluate and make decisions. Wellness data can be accessed from a remote location via the Internet [18].

\section{IoT as an application: cloud-based building management systems for the Internet of things}

In this research, it shows of IoT as an application for the cloud-based building management system. Recently, excellent by the Internet of things (IoT), the age of everything linked to computers is coming. However, the applications hardly demonstrate how autonomous communication is applied to it and how self-cooperation is applied to realworld environments. They have proposed a smart building
Fig. 3 Functional description of the developed smart home monitoring system [18]

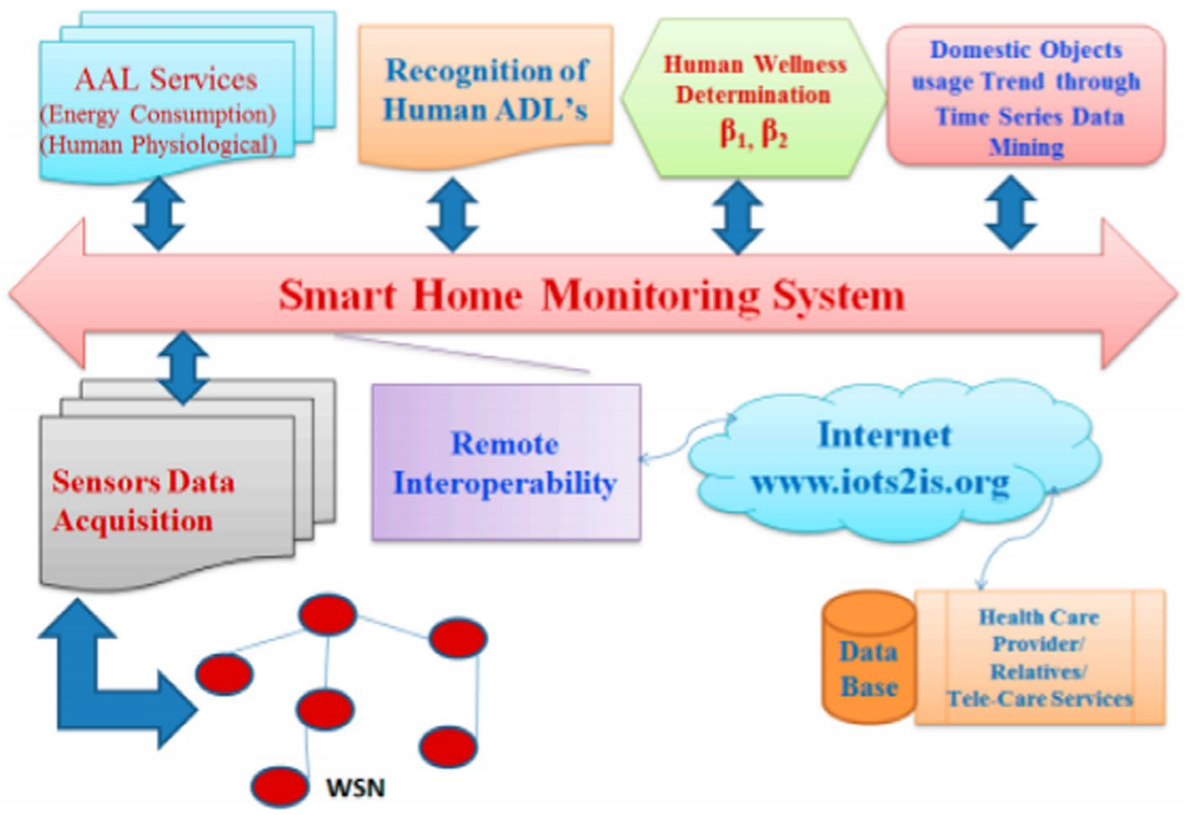


on IoT and cloud-based technologies to conduct collaboration and productive activity in buildings and facilities with various sensing devices. Smart construction is critical because a large amount of building energy is used by the building management system [19].

The proposed network consists of four modules, including Smart Construct, Data Centre, Building Energy Projection (BEF), and the BMMC server, as shown in Fig. 4. The datacenter has a cooling energy data update and an energy prediction module. A local agent is present in each building. Different elements (sensor devices) are available for collecting real-time data on building resources such as humidity, outside temperature, discomfort index, solar irradiation index, and wind speed [19].

\section{loT-fog-cloud-based architecture for smart city: Prototype of a smart building}

The research was conducted by Joy Dutta and Sarbani Roy, Department of Computer Science and Engineering, University of Jadavpur, Kolkata, India [20]. They introduced a prototype of an intelligent building for intelligent cities using emerging technologies like IoT, fog, and cloud. Demand for intelligence increases frequently, but the main stumbling block is its high price. Thus, their goal is to enhance the home and office quality of life by offering newly improved workplaces. The entire system is automated, functional, and controlled by the user through his/her smartphone or computer; however, the costs remain within an expected human budget. The IoT, fog, and cloud convergence is all accomplished, and the assimilation is performed by open-source hardware and software to reduce costs significantly. Moreover, it over other existing solutions and incorporating them in an ideal and creative way without sacrificing the quality of service that other existing solutions provide a QoS (quality of service) [20]. The designed intelligent construction framework is a three-tier architecture, as shown in Fig. 5. The following definition is given as:

\section{(i) IoT layer}

Tier 1 integrates sensing and communication capacities into physical buildings to prepare them for IoT. The primary circuit diagram of interfacing for this approach is shown in Fig. 6.

For the monitoring of sensors and communication devices, a microcontroller is used. Now, these things can feel the environment and communicate through Bluetooth or Wi-Fi with other devices. Many such items can be found in smart construction applications. For Arduino, a relay module controls a group of high-voltage electrical devices [20].

(i) Fog layer

In Tier 2, the fog portal server is held, and some local decisions can be made based on the sensor's data. The data is stored, filtered, and pre-processed by this layer. It also acts as an Internet gateway to connect IoT via VPN with the Internet.
Fig. 4 System architecture for smart buildings management [19]

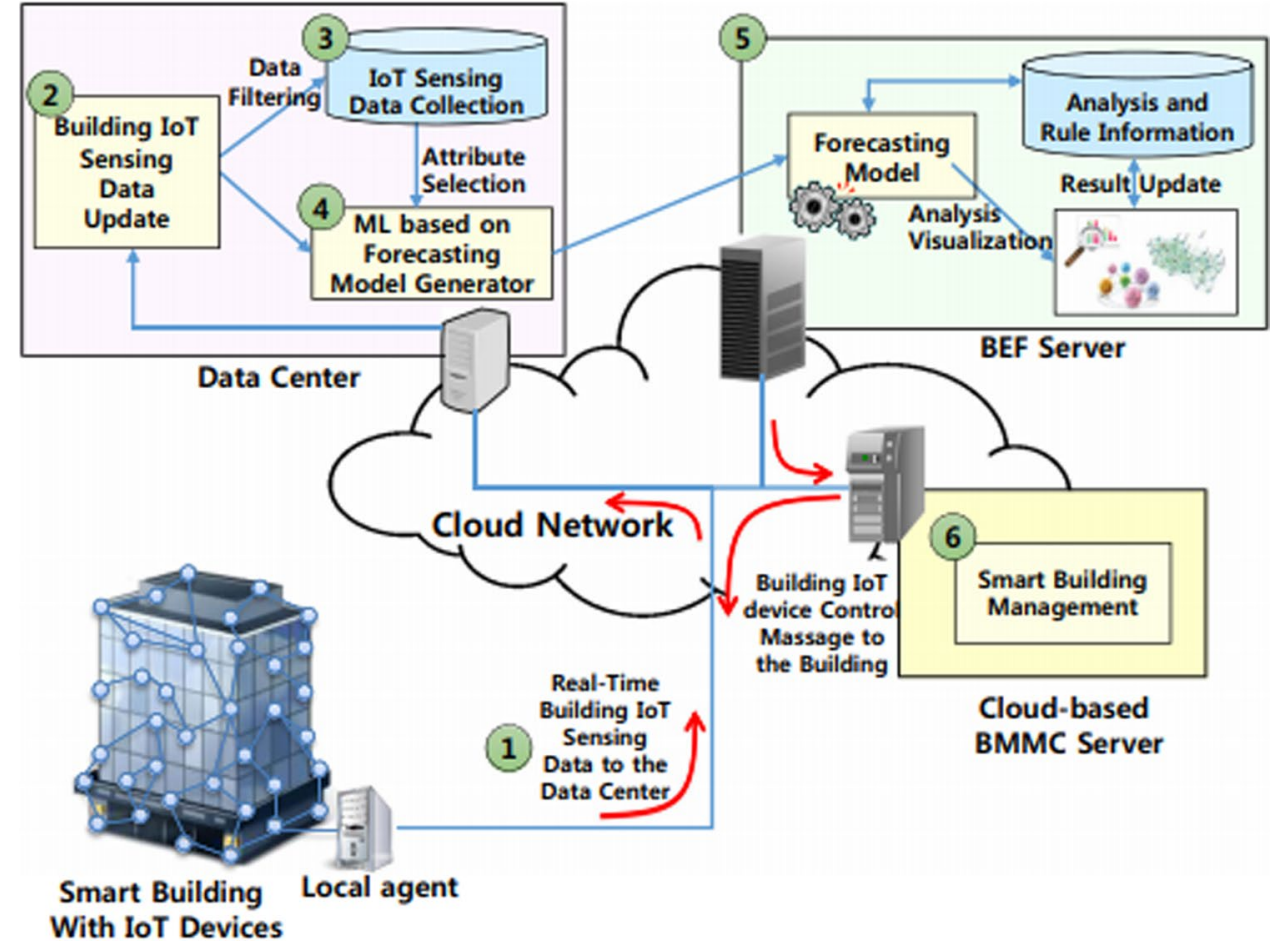



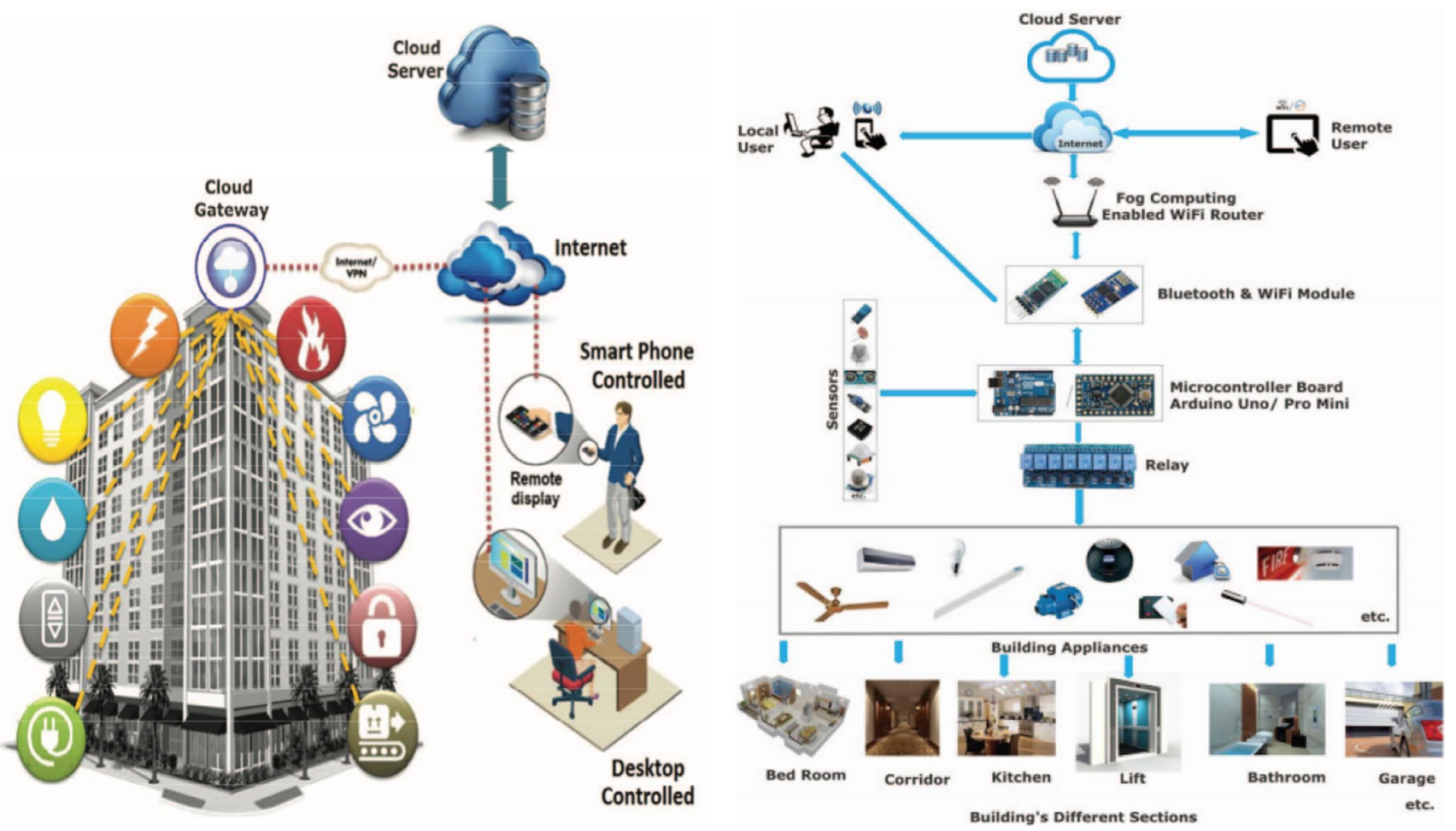

Fig. 5 Architectures of the smart building in terms of circuit and design [20]

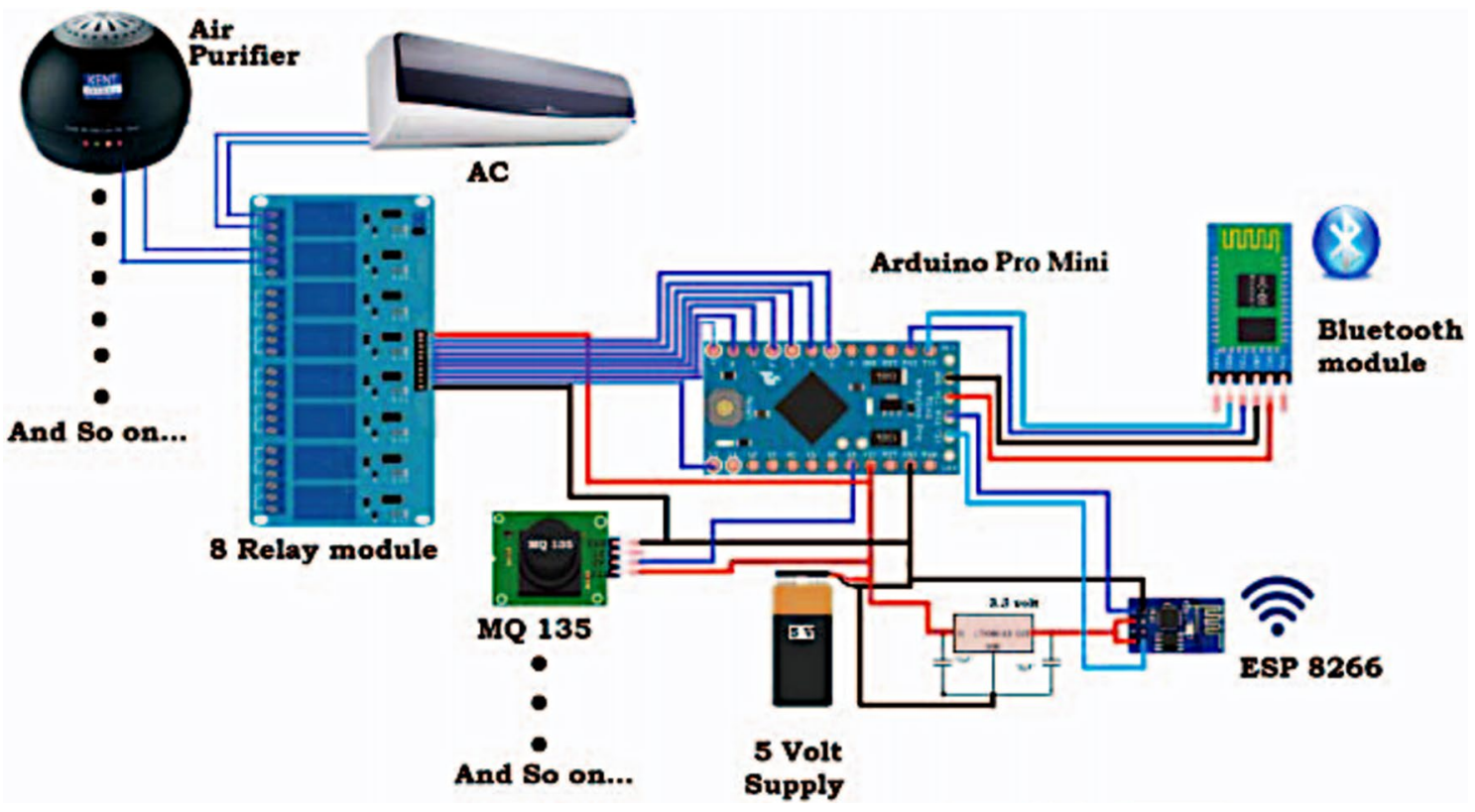

Fig. 6 Circuit diagram of smart controlling and interfacing systems [20] 
(ii) Cloud layer

In Tier 3, fog-layer data is transmitted to the cloud for storage and computation; a cloud servercontrolled database is maintained for smartphone or device IoT control.

\section{Thermal image scanning for influenza border screening: Results of an airport screening}

This study demonstrates how seasonal influenza B is detected at airports. Thermal infrared image scanning (ITIS) was used in 1275 aviation travelers who agreed to measure tympanic and respiratory temperatures for dermal temperatures. In the recipient operating characteristic curves (ROC), the ITIS predictive of tympanums temperatures $\left(37.8^{\circ} \mathrm{C}\right.$ and $37.5^{\circ} \mathrm{C}$ ) and influenza infection was assessed, and the sensitivity, specificity, and predictive positive (PPV) estimates were calculated. In total, during this time of the study, 5,274 travelers returned a questionnaire, of whom $823(15 \%)$ were by definition symptomatic [21]. Figure 7 shows the pathway of potential participants through the study.

\section{Thermal imaging today and its relevance to diabetes}

This study was carried out in diabetes and thermal imaging by Francis Ring [22]. Consequently, the infrared imagery offers details about the distribution of skin temperature. Because the human body's environment influences this (Fig. 8), it is vital for any experiments using this approach to be as objective as possible and standardized. A significant benefit of thermal imaging is its non-contact and non-invasive characteristics. The camera simply receives the typical thermal energy released by the body by remote temperature sensing. Since the imaging process does not use harmful resources, it is quite acceptable over time to repeated research [22].

\section{Variables to be controlled for smart infrastructure building}

As the current situation and demanding, the variables needed to be controlled and to be understood. For thermal scanning and face recognition, there are many variables to

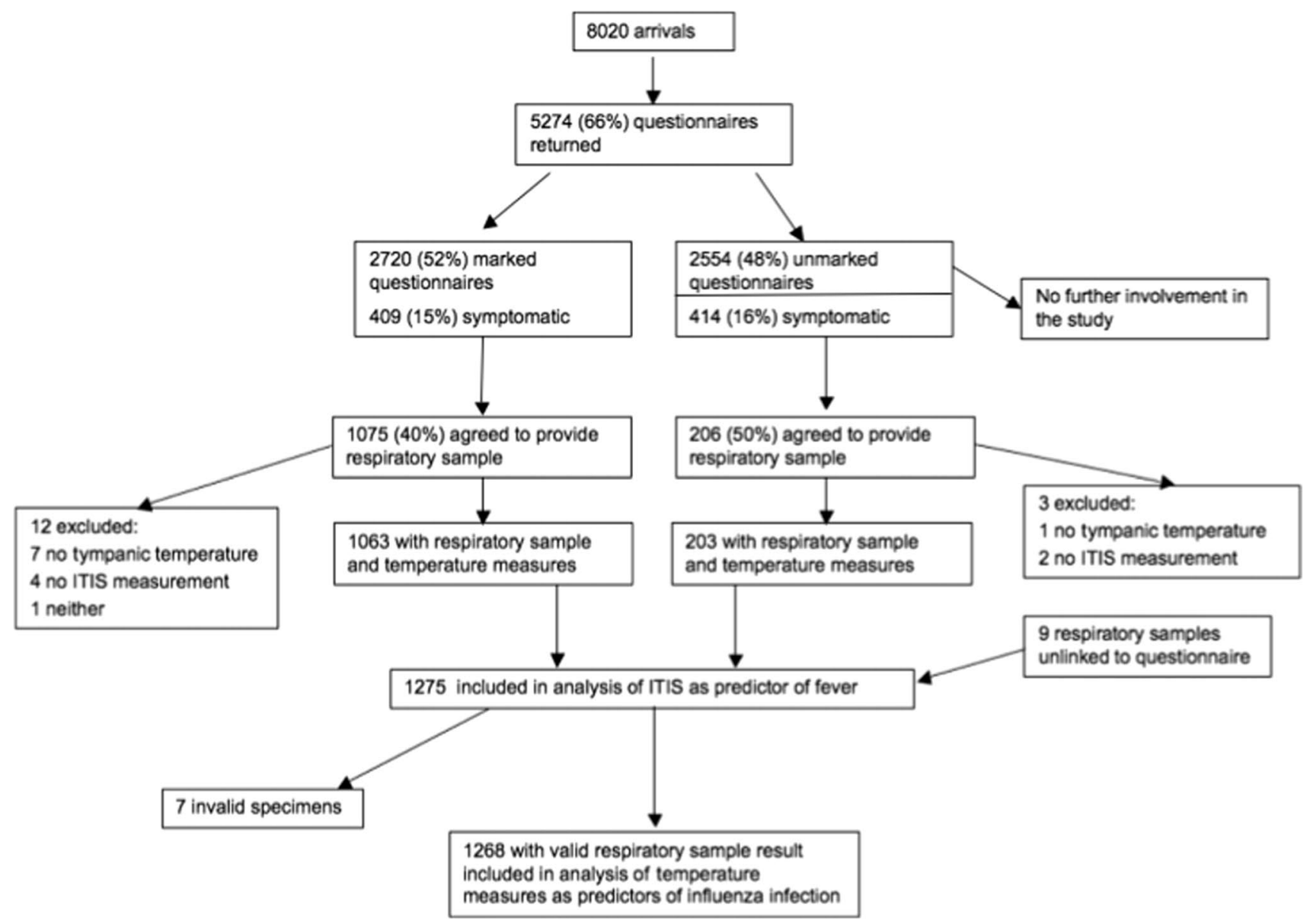

Fig. 7 Study of flow chart showing how participants were selected from arrivals during the study period [21] 
Fig. 8 Standard views for infrared thermography [22]
Anterior
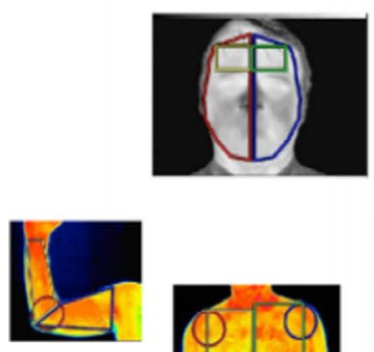
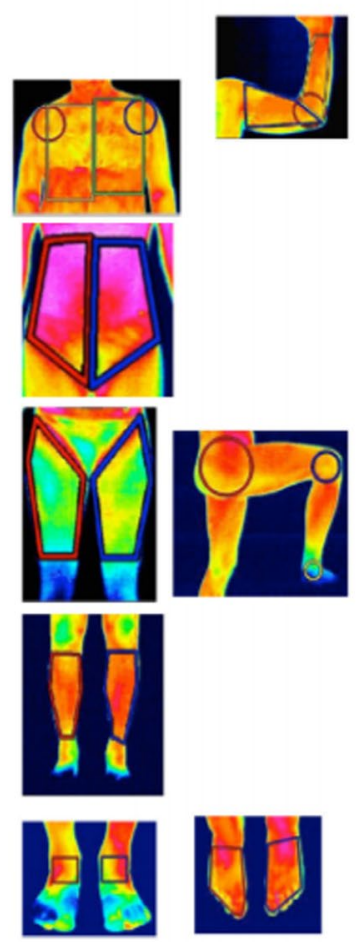

Posterior
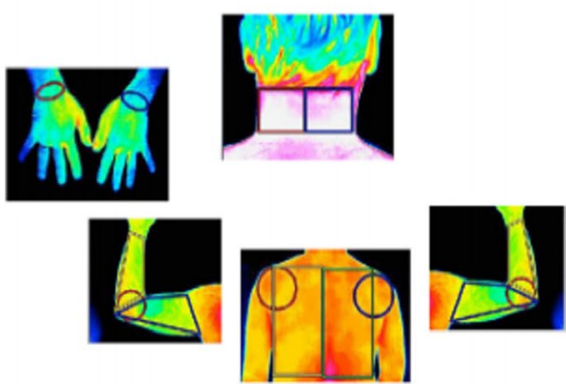
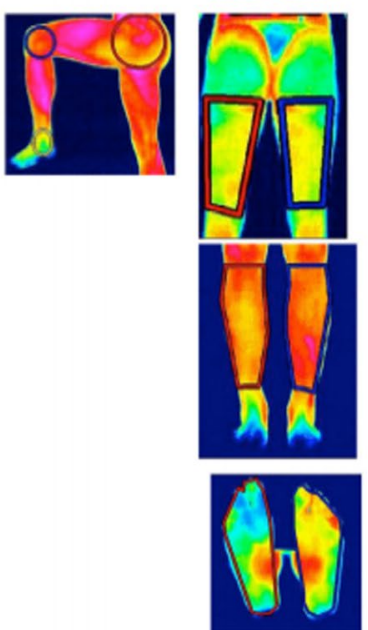

be controlled and discovered. Firstly, the situation of infrared thermal image scanning needs to be thoroughly researched. There are different types of infrared cameras in the market. Every type has ranges, the difference in price, and specifications. Here in this system, the camera that will be used is Adafruit AMG8833 thermal infrared camera. This type of camera is an $8 \times 8$ grid thermal IR sensor from Panasonic, and it offers an increase in performance than its predecessor, the AMG8831. This component will calculate temperatures between $0{ }^{\circ} \mathrm{C}$ and $80^{\circ} \mathrm{C}\left(32^{\circ} \mathrm{F}\right.$ to $\left.176^{\circ} \mathrm{F}\right)$ with a precision of $\pm 2.5^{\circ} \mathrm{C}\left(4.5^{\circ} \mathrm{F}\right)$. It can detect a person from up to $7 \mathrm{~m}$ away. This improvement shows that the proposed system is suitable to be used with this type of thermal infrared camera as it can be used to detect a person up to $7 \mathrm{~m}$ and has to be considered on how to mount this system inside a building. It is recommended to be used in the entrance and close quarters, such as elevators, stairs, and even doors.

Moreover, the other variable that needs to be controlled is the face recognition system. As we can agree and understand, biometrics are used by a facial recognition program to map facial features from an image or video. To find a match, it compares the details to a database of recognized faces.
As we are using this system, a data cloud is used in order to detect the amount of face recognition data stored. Many algorithms can be used as well as data of face stored in the data cloud. For example, the facial recognition system algorithm can be used for front facial scanning only or front and side facial scanning. The algorithm that we choose inside the system is crucial as it is a variable that has to be controlled. For this variable, it is to maintain the facial scanning angle and algorithm chosen for the system to get a precise face recognition scan.

\section{Open challenges, perspectives, and new directions}

As it is well known in the industry, there are quite a few products that can serve thermal infrared scanning and face recognition; however, these systems can be used as a continuous thermal scanner in scanning people walking by or coming through the building. Therefore, the challenge is designing a system that can be used simultaneously as both a thermal scanner and a face recognition system. In the market 
Table 1 Summary of the recent systems and devices

\begin{tabular}{|c|c|c|c|c|}
\hline Author/company & Product & Advantages & Disadvantages & Ref \\
\hline Swann & $\begin{array}{l}\text { Swann Thermal Sensing PIR Security } \\
\text { Camera }\end{array}$ & $\begin{array}{l}\text { Long-range night vision } \\
\text { Outdoor use rating ip } 66 \text {, with weather- } \\
\text { proof }\end{array}$ & $\begin{array}{l}\text { The local connection uses DVR } \\
\text { Low view angle }\end{array}$ & [23] \\
\hline Swann & $\begin{array}{l}\text { Swann 1080p Alert Indoor Security } \\
\text { Camera }\end{array}$ & $\begin{array}{l}\text { Wireless connection } \\
\text { Two-way audio } \\
\text { Wider viewing angle }\end{array}$ & $\begin{array}{l}\text { Not weatherproof, indoor use only } \\
\text { The short range of night vision }\end{array}$ & [24] \\
\hline Yobekan & $\begin{array}{l}\text { Yobekan KV-11 Non-contact Thermom- } \\
\text { eter Gun }\end{array}$ & $\begin{array}{l}\text { Cheap production } \\
\text { Small and portable }\end{array}$ & $\begin{array}{l}\text { The short range of scanning } \\
\text { Short infrared temperature range }\end{array}$ & [25] \\
\hline Fluke & $\begin{array}{l}\text { Fluke } 568 \text { Contact \& Infrared Temp } \\
\text { Gun }\end{array}$ & $\begin{array}{l}\text { The more extended range of scanning } \\
\text { Higher infrared temperature range }\end{array}$ & $\begin{array}{l}\text { No thermal imaging system } \\
\text { Manual operation } \\
\text { Expensive }\end{array}$ & [26] \\
\hline PerfectPrime & PerfectPrime IR0001 Thermal Camera & $\begin{array}{l}\text { Showing range of temperature on the } \\
\text { screen } \\
\text { Better temperature range than cheap } \\
\text { temperature gun }\end{array}$ & $\begin{array}{l}\text { Manual operation } \\
\text { Expensive }\end{array}$ & [17] \\
\hline
\end{tabular}

for this device, there is no software or coding available yet. This is a challenge to solve, as this is a modern method.

The specific viewpoint of this whole system is to help and promote community support for the medical authorities while promoting management protection. To warn them to be prepared and ready at any time if there is any potential future scenario. These systems are assessed (Table 1) to help the country improve and encourage workers' access to work and facilitate pedestrians' access to and from buildings.

\section{Conclusion and future directions}

The pandemic of COVID-19 brings distinct changes to society, and thus, humanity must make plans and adopt the steps for future outbreaks of disease. Residential buildings are vital to the welfare of the population as they assess social well-being. Homes were of vital importance during locking times during which people were forced to stay home to avoid the spread of infection. The essence of this home quarantine experience varies from person to person. This calls for a substantial rethink of housing to brace humanity for potential future outbreaks of disease.

With the devastating effect of COVID-19 on people worldwide, researchers from various fields are increasingly committed to addressing current and possible pandemic solutions through technology diversity. Researchers should address this latest major challenge and demonstrate how technical analysis would help us understand the technology's mechanism and make the world safer. In addition, learning from this pandemic and learning to solve significant problems and related to facilitating the SDGs in the future are essential. Therefore, this article summarizes recent researchers on how to solve the most recent hassle issue that we are facing nowadays. As a group, we are embarking on an increasingly critical journey to tackle COVID-19 spreading by advancing digital sustainability values and practices.

Acknowledgement The authors gratefully acknowledge the provided facilities by Management and Science University (MSU).

\section{Compliance with ethical standards}

Conflict of interest The authors have no conflict of interest with the submitted manuscript.

\section{References}

1. Al-Humairi SNS, Mazlan N, Tarofder APDAK, Razalli H (2020) COVID-19 PANDEMIC: Monitoring Technologies. White Falcon Publishing, Healthcare and Panic buying behaviour

2. Oldstone MB (2020) Viruses, plagues, and history: past, present, and future. Oxford University Press, Oxford

3. Al-Turjman F, Nawaz MH, Ulusar UD (2020) Intelligence in the Internet of medical things era: a systematic review of current and future trends. Comput Commun 150:644-660

4. Aziz NA, Othman J, Lugova H, Suleiman A (2020) Malaysia's approach in handling COVID-19 onslaught: Report on the Movement Control Order (MCO) and targeted screening to reduce community infection rate and impact on public health and economy. $\mathrm{J}$ Infect Public Heal 13(12):1823-1829

5. Gankidi P, Dadi S (2020) Novel Covid-19 Detection and Diagnosis System Using IOT Based Smart Helmet. A J Compos Theory XIII(IV) 457-465

6. Han Y, Yang H (2020) The transmission and diagnosis of 2019 novel coronavirus infection disease (COVID-19): A Chinese perspective. J Med Virol 92(6):639-644

7. Bai L et al (2020) Chinese experts' consensus on the Internet of Things-aided diagnosis and treatment of coronavirus disease 2019 (COVID-19). Clin eHealth 3:7-15

8. Singh RP, Javaid M, Haleem A, Suman R (2020) Internet of things (IoT) applications to fight against COVID-19 pandemic, 
Diabetes \& Metabolic Syndrome: Clinical Research \& Reviews 14(4):521-524

9. Khetrapal S, Bhatia R (2020) Impact of COVID-19 pandemic on health system \& sustainable development goal 3. Indian J Med Res 151(5):395

10. Van Natta M, Chen P, Herbek S, Jain R, Kastelic N, Katz E, Struble M, Vanam V, Vattikonda N (2020) The rise and regulation of thermal facial recognition technology during the COVID-19 pandemic. J. Law Biosci 7(1):1-17

11. Razalli H, Alkawaz MH and Suhemi AS (2019) "Smart IOT Surveillance Multi-Camera Monitoring System," in 2019 IEEE 7th Conference on Systems, Process and Control (ICSPC), 2019: IEEE, pp. 167-171.

12. Hossain MS, Muhammad G, Guizani N (2020) Explainable AI and Mass Surveillance System-Based Healthcare Framework to Combat COVID-I9 Like Pandemics. IEEE Network 34(4):126-132

13. Al-Humairi SNS, Zainol MH, Razalli H, Raya L, Irsyad M (2020) Conceptual Design: A Novel Covid-19 Smart AI Helmet. Int J Emerg Technol 11(5):389-396

14. Jones R, Meyer C, Wolf L (2013) Solar Powered PIR Security System to Monitor Wildlife, Digital Library, pp 1-15

15. van Wyk D (2018) Helpful home gadgets: lifestyle gadgets. Without Prejudice 18(4):53-53

16. Hancer M, Arkaz H (2015) A facile fabrication of superhydrophobic nanocomposite coating with contact angles approaching the theoretical limit. Appl Surf Sci 354:342-346

17. PerfectPrime. "IR0001 Thermal Camera with IR Resolution 1024 Pixels." Perfectprime. https://perfectprime.com/pages/contact-us (Accessed 07.09.2020, 2020).
18. Ghayvat H, Mukhopadhyay S, Gui X, Suryadevara N (2015) WSN-and IOT-based smart homes and their extension to smart buildings. Sensors 15(5):10350-10379

19. Yu J, Kim M, Bang H-C, Bae S-H, Kim S-J (2016) IoT as a applications: cloud-based building management systems for the internet of things. Multimed Tools Appl 75(22):14583-14596

20. Dutta J and Roy S (2017) "IoT-fog-cloud based architecture for smart city: Prototype of a smart building," in 2017 7th International Conference on Cloud Computing, Data Science \& Engineering-Confluence: IEEE, pp. 237-242.

21. Priest PC, Duncan AR, Jennings LC, Baker MG (2011) Thermal image scanning for influenza border screening: results of an airport screening study. PLoS ONE 6(1):e14490

22. Ring F (2010) Thermal imaging today and its relevance to diabetes, J. Diabetes Sci. Technol 4(4):857-862

23. Swann. "Swann Thermal Sensor Outdoor Security Cameras 2 Pack: 1080p Full HD with IR Night Vision \& PIR Motion Detection-SWPRO-1080MSBPK2." https://www.swann.com/uk/swpro -1080msbpk2 (Accessed 9th September 2020).

24. Swann. "1080p Alert Indoor Security Camera." https://www. swann.com/us/swifi-alertcam (Accessed 2020).

25. Yobekan. "KV-11 Non-contact Infrared thermometer." https:// www.facebook.com/Yobekanindia/. (Accessed 10 June 2020).

26. Fluke. "568 Contact \& Infrared Temp Gun." https://www.fluke .com/en-my/product/temperature-measurement/ir-thermometers/ fluke-568 (Accessed 10 August 2020). 